\title{
The Gravity Model on EU Countries - An Econometric Approach
}

\author{
Marku Megi ${ }^{1}$
}

\begin{abstract}
Foreign Direct Investment, play a huge role in the growth of the global businesses. They can provide to a firm, new markets where the firm can operate, new marketing channels, manufacturing facilities, access to technology and to the products, and they also provide techniques and funds previously unknown. For the host country, this source of technologies, capital, processes, techniques, and managerial skills can provide an important impetus to the economic development of the country. Through this study, it has been analyzed how FDI are affected by the distance and by the economic size of the country. Given that such a gravity model (size and distance) on FDI already exists, this research has examined particularly the impact of these two factors on FDI of the EU member states. Through an econometric model it has been examined how economic size and distance affect foreign investment of EU leading countries in some of the world states and which of two factors have had the greatest impact. The hypothesis raised in this paper is related to the fact that the gravity model with its factors is extremely important for the volume of FDI, the size playing a more important role than the distance. By using statistical judgment and econometric analysis it has been explored if the hypothesis rose above, is statistically valid or not. From the model resulted that the impact of the size coefficient on FDI is 0.0042 million Euros, while the distance coefficient is -0.36 millions. It shows that with the increase of GDP and the distance between countries, FDI increase and decrease respectively with the above coefficients. According to statistical methods of control, economic size was a more determinant factor than the distance, giving us the idea that in recent years with the increased role of globalization the importance of distance has significantly decreased. In this paper it is recommended the gravity models should consider a lot other factors besides size and distance.
\end{abstract}

JEL classification: A1, C01, C12, C31, C51, F21

Keywords: FDI, international trade, gravity model, EU countries, econometric model.

\section{Introduction}

This paper topic is related with gravity model on FDI. Despite that this model is often reviewed, this study will reevaluate the impact of the two main variables of this model, economic size and distance, specifically on Foreign Direct Investment of EU member countries. The primary goal in this case is to evaluate the hypothesis that the impact of economic size on FDI is greater than the impact of distance. Also through this study will 
be analyzed the individual role of each of the constituent components of the model giving us a more general overview of the distance and size.

In addition, the second part is related with the theoretical basis of gravity models since their first implementation in the social sciences till their latest appliance in economic sciences and mainly in the sector of international trade.

In the third part it will be studied each of the factors of the model, size and distance. It will be explained why economic size has a positive impact on investment and why the distance (in all its forms) affects negatively the trade flows.

The fourth part sees implemented practically what has been claimed by the current theories about gravity model in international trade. Thus, through a mathematical equation will be seen the foreign direct investment depending on two variables, distance and economic size.

At the conclusion of this paper there are provided some argument regarding the results of econometric model, by giving the necessary suggestions.

\section{Literature review on gravity models related to foreign direct investment}

The gravity model of trade in international economics, similar to other gravity models in social sciences, provides bilateral trade entries based on economic size (often used measurements of GDP), and the distance between the two units. This model for two countries ( $\mathrm{i}$ and $\mathrm{j}$ ) is as follows: $\mathrm{X}_{\mathrm{ij}}=C \frac{Y \mathrm{i} Y j}{D i j}$ where $\mathrm{X}_{\mathrm{ij}}$ is the entry from trade, $\mathrm{Y}$ is economic size in each country, and $\mathrm{D}$ is the distance, while $\mathrm{C}$ is a constant. The model has been used in international relations to evaluate the impact of trade and trade alliances and has been used to test the effectiveness of trade agreements and organizations such as the North American Free Trade Agreement (NAFTA) and the World Trade Organization (WTO).

In the 60th gravity models were applied to analyze international trade flows. Pioneers in these studies were: Linemann [1963], Pöyhönen [1963], Pullainen [1963] and Tinbergen [1962]. However the most famous is the study proposed by Tinbergen which has been declared as a discoverer of the law of gravity (gravity equation) in the international economy; $\mathrm{X}_{\mathrm{ij}}=C \frac{Y I Y j}{D i j}$. The gravity equation indicates that the amount of flow between the two countries grows directly with their economic size and decrease depending by their transport costs which are measured by the distance between the economic centers of the two countries.

Although, there are many variables that can embody countries economic measures, in the studies of bilateral trade and direct investment flows, the economic size of the exporting countries and importing countries is usually measured by the gross domestic product. However, economic size can be measured by population, by domestic product per capita or by production factors power (absolute value or per capita). Given that there are a number of methods for measuring gross domestic product; in current prices, in constant prices or by purchasing power it is questionable which of them is the most appropriate for gravity models.

The distance in the universal law of gravitation illustrates the resistance of attraction forces between two points. In international trade resistance force of gravity between the two countries is embodied in all those factors that hinder the international flows of 
goods, services, capital, labor and technology. These factors can be divided into two groups: economic and non-economic. The first group includes: geographical distances between countries economic centers, proximity, characteristics of geographical location, cultural similarities, the volatility of exchange rates, tariffs and trade barriers, membership in international organizations and the quality of infrastructure. The second group includes: regulations, political conflicts and environmental barriers.

Recently the gravity model has become a very popular analytical tool in explaining bilateral capital flows, especially in explaining the determinants of foreign direct investment (FDI). In the past ten years the FDI gravity models have become very popular.

\section{Economic size and distance}

Three of the biggest economic European partners of the United States are Germany, Britain and France. These are the three largest economies in the European Union; meaning have the highest values of gross domestic product (GDP) among other EU countries. On the other hand, the biggest partners of Europe are USA, China, Japan and Brazil who are the most powerful economies in the world. The above two facts may be indicative of the role of the economic size in international trade direction. Hence, a strong relationship between a country's economic size and the volume of trade flows is expected. Each country will naturally choose to trade with economically powerful countries; however a trend of powerful countries with emerging economies has been noticed recently.

A large state has economies of scale because the cost per unit of produced output is lower. This is because the major economies have a large number of populations which pays more taxes that directly impact the product cost. Lower costs per unit will bring increasing revenue of scale. Moreover, being a great state give the possibility of having more human capital which will transmit more knowledge. If being a great country would only have benefits then the world should be organized in a single state (the merging of many different countries in a single market justify this), but this would not be possible because the administrative costs would outweigh the above benefits.

The table below (table1) shows that larger countries and economies like USA, Canada and Russia have the highest FDI flows. Numerous studies have shown that the country's GDP has been and remains a determinant of FDI, so the market size that represents the first component of the gravity model affects positively the FDIs.

Distance is the second important component of the gravity model. Unlike the size of the country that has a positive impact on trade flows, distance adversely affects them. So as far away are two countries, as lower is the chance that they have commercial exchanges with each other. It is estimated by various econometric models that if the distance between two countries is increases by $1 \%$ the trade between them will decrease from $0.7 \%$ to $1 \%$. Concrete cases of different countries confirm this. Thus Mexico and Canada prefer to trade more with the U.S. and less with Europe. Also many free trade agreements have been concluded between countries that have geographic proximity. It can be mentioned the EU (European countries), NAFTA (North American countries), APEC (transpacific countries), MERCOSOUR (Argentina, Brazil, Paraguay, Uruguay), CARICOM (Caribbean English-speaking countries), ANCOM (Bolivia, Ecuador, Peru, 
Colombia) and many other agreements. So in this case the distance more than a driving factor would be considered as a barrier for the trade between two countries.

The question that arises spontaneously in this case is: Why the distance is so important in influencing trade flows between two countries. The answer comes naturally: transportation costs. Precisely these latter are those that hinder and block the implementation of trade exchanges between the two countries that are not so close geographically. Therefore, two states that have significant geographical distance from one another will experience higher costs in the export and import of their goods. So the trade between two countries tends to be more intense if the states are close between them and less intense if they are remote. The distance between the two countries isn't only geographical; it can be also cultural. This latter is defined as a set of norms and values which taken together constitute a way of life. So countries that have similar cultures are more likely to export and import with each other, than those countries whose cultures differ greatly. For the Balkan countries it easier to trade with Mediterranean countries than with the Nordic ones and it cannot be explained only by transportation costs, but also by the fact of the different cultures. Another form of distance and it is the linguistic one. Language is the main means of communication and on the basis of this latter it's accomplished everything. If it is analyzed the example of the U.S., which has more trading relationship with Canada, we will see that a crucial factor in this relationship, is the language. Canada and the U.S. have the same official language so communication between firms that enter into trade agreements with each other is much easier than between two countries that have quite different languages.

Distance can be measured and expressed, even in the context of the time. The more two countries are far from each other the more time will be needed to perform commercial transactions and this can result in inefficient market.

According to the theorists, globalization has diminished the importance of role of distance in the determination of the trade flows. Globalization is related with the global trend towards a more integrated and interdependent economy. Thus national markets are merged into a single global market and the production of products is transferred to those countries where they are produced in the most efficient way. Viewed by this perspective can be concluded that distance plays no role in the trade as long as we have a global market. But the globalization process isn't yet fully achieved, so the importance of distance might have been reduced but it has not yet lost its power.

\section{The methodology}

The essential purpose of this section is to estimate that direct investment flows between EU Member States and the rest of the world are defined by the standard variables included in gravity models such as: total gross domestic products of the country "Home" and the distance between them. The raised hypothesis is that the distance and the size are statistically significant in magnitude of foreign direct investment of European Union countries. The impact of these two factors on FDI is measured through statistical methods such Fisher statistic (F), Student statistic ( $t$ ), p value (p) and coefficient of determination $\left(\mathrm{R}^{2}\right)$. 


\subsection{The data}

The data are taken from the official website of EU statistics (Euro stat) and are of the year 2012 since this was the last year in chronological order, for which were available and complete data about the three variables related to this study. The data related to the GDP of different countries of the world are taken from the official website of the World Bank. The FDI data and the GDP data are expressed in million Euros. Since there were no available data in euro about countries' GDP than by using an average exchange rate of 2012 the USD data were converted in Euro data. The statistical method that it is used is the method of the ordinary least squares, according to which can be build different econometric models. The statistics used to control the importance of parameters are the Fisher statistic, the $t$ statistic, the $R$ square (coefficient of determination) and the $p$ value. The level of importance selected to check the hypothesis is $\alpha=0,05$. The method of operation has been as following; First have been built the hypotheses, then has been seen the impact of each of the two factors separately on FDI and in the end has been seen the impact of the two together on FDI. There are three variables that are taken into consideration; two explanatory variables (GDP and the distance) and one dependent variable (FDI). The program that has been used is the statistical program EViews and the tables that have resulted from data processing are presented simultaneously with the estimation of equations. Only completely linear models are built, given that there are negative values of FDI which do not allow the usage of logarithmic form. The selection of the final model is made based on the coefficient of determination, because the model with the highest $\mathrm{R}$ square coefficient is the model that represent best the reality.

\subsection{The econometric model about the impact of size and distance on foreign direct investment}

Up to this part of the paper it is spoken theoretically about the foreign investment as an instrument of international trade, about the gravity model and about its two main components, the size and distance. So everything is analyzed generally based in theories given by various authors, but the impact of the gravity model should be analyzed by seeing concrete examples. In this paper are analyzed EU investments in 17 countries around the world ranging from Asian countries (Singapore, China, India, Japan, Indonesia, Malaysia, and Thailand), Oceania country (New Zealand) African countries (Egypt, Nigeria), the South American countries (Brazil and Argentina), North American countries (USA and Canada), Australia as well as Russia and Turkey which partly belong to Asia and partly to Europe, and are not part of the EU. There are analyzed the EU foreign investment in these countries. The distance is measured between the original centre of the Euro zone, France and countries economic center. It is measured in crow flies and it is expressed by the European measuring unit, kilometers. The size of the countries is measured by the nominal GDP of each country in millions of euro.

At first the dependence of FDI from distance variable is analyzed, using the method of the ordinary least squares. The competing hypotheses in this case would be: $\mathrm{H}_{0}$ : Distance is not a statistically significant factor for the size of FDI of EU countries $\mathrm{H}_{\alpha}$ : Distance is a statistically significant factor for the size of FDI of EU countries 
Table 1- Foreign direct investment of European Union in some of the main countries of world

\begin{tabular}{|l|l|l|l|}
\hline State & FDI (million euro) & Distance & GDP (million euro) \\
\hline Argentina & 2457 & 11477.726 & $369,941.89$ \\
\hline Australia & 11571 & 15176.095 & $1,192,218.44$ \\
\hline Brazil & 22227 & 8634.957 & $1,752,580.19$ \\
\hline Canada & 17568 & 6848.460 & $1,417,074.05$ \\
\hline China & 15516 & 8030.981 & $6,400,713.24$ \\
\hline Egypt & 4542 & 3315.473 & $204,484.10$ \\
\hline Indonesia & 2547 & 11734.665 & $683,120.40$ \\
\hline India & 5484 & 7377.156 & $1,432,856.32$ \\
\hline Japan & 1444 & 9861.138 & $4,636,680.65$ \\
\hline Malaysia & & 10427.010 & $237,316.49$ \\
\hline Nigeria & 4440 & 4180.654 & $204,301.66$ \\
\hline New Zealand & -569 & 19200.927 & $130,196.57$ \\
\hline Russia & -1087 & 6228.097 & $1,567,501.61$ \\
\hline Singapore & 16170 & 10799.468 & $213,718.53$ \\
\hline Thailand & -8895 & 2802.003 & $284,722.62$ \\
\hline Turkey & 749 & 7674.171 & $614,044.95$ \\
\hline United States & 4430 & & $12,638,352.89$ \\
\hline
\end{tabular}

The selected model is a fully linear form, and theoretically has the following form:

FDI $=$ C (1) + C (2)*DISTANCE

If the distance varies with $1 \mathrm{~km}$ the size of FDI will change by $\mathrm{C}$ (2). Specifically this equation would be:

FDI $=15479.8103498-0.721656267212 *$ DISTANCE

So for every increase of distance with $1 \mathrm{~km}$, FDI will decrease with 0.72 million euro. There is a negative relationship between the two variables which is affirmed also by the law of gravity for international trade. In order to view the statistical significance of this relation there are analyzed four parameters that are given in the following table:

Table 2-Dependent variable (Distance) parameters

\begin{tabular}{|l|l|}
\hline Parameter & Coefficient \\
\hline R-squared & 0.033851 \\
\hline t-Statistic & -0.724951 \\
\hline F-statistic & 0.525554 \\
\hline Prob. & 0.4796 \\
\hline
\end{tabular}

The first parameter would be the $t$ statistics which in this case is -0.72 . In the moment that $|\mathrm{t}|>2$, the explanatory variable would be important. Since in the present case $|\mathrm{t}|$ $<2$ then the distance according to this statistic is not statistically significant. The second parameter is Fisher's statistics, which must be greater than 5 in order to return this equation into a model. In the actual case Fischer will be 0.52 confirming what was stated above through $\mathrm{t}$ statistic. The third parameter to be examined will be the $\mathrm{p}$ value. This value is compared with the criteria of significance $\alpha$, which in this study is taken $5 \%$. The 
distance will be a statistically valid explanatory when $\mathrm{p}$ value is less than the value of $\alpha$. The table shows that the value of $\mathrm{p}$ is $0.4796(47.96 \%)$, meaning that in this case the distance is not an important variable to explain the size of European FDI in the world. The last parameter is $\mathrm{R}^{2}$. This parameter takes values from 0 to 1 and indicates the strength of the connection of variables or to what extent the variation of the independent variable is explained by the variation of explanatory variable. In the concrete case the coefficient of determination is 0.033 showing that the variation of FDI depends $3.3 \%$ from the distance variation. In conclusion it can be said that from the evaluation of the four parameters the hypothesis that the impact of distance is statistically significant for the size of FDI is rejected in the case of the European Union.

The same analysis will be conducted also for the second explanatory variable that is the size of the host country. As size evaluation is taken the value of gross national product of the country where it is invested. The hypotheses in this case will be:

$\mathrm{H}_{0}$ : The size of the host country is not a statistically significant factor for the size of EU countries

FDI.

$\mathrm{H} \alpha$ : The size of the host country is a statistically significant factor for the size of EU countries FDI.

Theoretically the derived equation is:

$\mathrm{FDI}=\mathrm{C}(1)+\mathrm{C}(2) * \mathrm{GDP}$

It is completely linear form and shows that if the country's GDP varies with 1 million then the impact it will have on FDI is C(2) million.

Concretely this equation would be:

FDI $=455.52798678+0.00426350123728^{*}$ GDP

So if the GDP of the host countries grows by 1 million euro, EU foreign investment in these countries will increase by 0.004 million Euros. The relationship between these variables is direct because the economic size of countries affects positively the FDI. The evaluation of the statistical significance of the explanatory variable is as follows.

Table 2 - Dependent variable (Size) parameters

\begin{tabular}{|l|l|}
\hline Parameter & Coefficient \\
\hline R-squared & 0.718898 \\
\hline t-Statistic & 6.193658 \\
\hline F-statistic & 38.36140 \\
\hline Prob. & 0.0001 \\
\hline
\end{tabular}

The table shows that the absolute value of statistics $t$ is greater than $2(t=6.19)$ making economic size a significant explanatory variable with impact on investment. Regarding Fisher statistic it is 38.36 therefore greater than the value with which it is to compare (5), and so by this estimator parameter, the economic size' variable is statistically valid. The same conclusion would be drawn if it is analyzed p value, which is 0.0001 , so many times smaller than 0.05 (the value of $\alpha$ ). Meanwhile the coefficient of determination shows that FDI is explained up to $71.8 \%$ by the variation economic size. So in this case the hypothesis stands and it can be argued that GDP as an explanatory variable is statistically significant in the impact on foreign investment. 
The final equation to be analyzed is the one that expresses the relationship of FDI simultaneously by the distance and by the economic size. The theoretical form and the concrete form of the equation are as follows:

FDI $=\mathrm{C}(1)+\mathrm{C}(2) * \mathrm{GDP}+\mathrm{C}(3) *$ DISTANCE

FDI $=3826.66565114+0.00421270868768 *$ GDP $-0.362875009238 *$ DISTANCE

Economic size impact on investment is 0.0042 million for a GDP growth by 1 million, while the increase of the distance in crow flies between EU countries and different countries of the world with $1 \mathrm{~km}$, would impact negatively on investment by 0.36 million. To see the importance of the two variables simultaneously on FDI, are studied the given parameters in the following table.

Table 3 - Dependent variables (Size and Distance) parameters

\begin{tabular}{|l|l|}
\hline Parameter & Coefficient \\
\hline R-squared & 0.727355 \\
\hline t-Statistic (size) & 5.967462 \\
\hline t-Statistic (distance) & -0.658981 \\
\hline F-statistic & 18.67440 \\
\hline Prob. (size) & 0.0001 \\
\hline Prob. (distance) & 0.5206 \\
\hline
\end{tabular}

The $\mathrm{t}$ statistics gives almost the same results that gave separately for each of the parameters, so the economic size has a more significant impact on the volume of EU foreign investment than the distance. Through Fisher $(\mathrm{F}=18.67)$ it is consider that this equation can be used as a model. $\mathrm{P}$ values for each explanatory variable support what was concluded above. Meanwhile the $\mathrm{R}$ square coefficient of $72.73 \%$ shows to which level this equation approximates reality. So to the EU investments in world are explained $72.73 \%$ by the economic size and by the distance.

Graphically the actual values and the expected values of FDI will be as follows:

GRAPH 1 - actual values of FDI

FDI

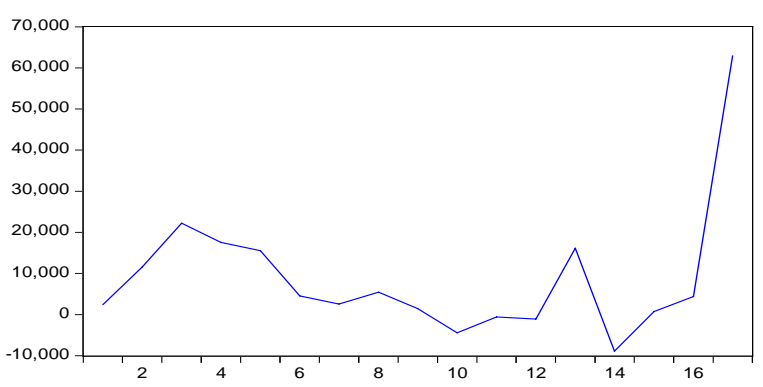

$\boldsymbol{G R A P H} 2$ - expected values of FDI calculated by the final equation

The countries are shown by numbers 1 to 17 as listed in the table 1 . 


\section{Conclusion}

The gravity model of trade in international economics, similar to other gravity models in social sciences, predicts bilateral trade entries based on economic size (often it used the GDP, and the distance between the two units). The size in the gravity model in the economy is measured mainly by the country's GDP and it is expressed more as the economic potential of the market. It has a positive impact on international trade, and consequently on foreign direct investment, thus affecting their growth. Distance is an important factor in the inward and the outward of foreign investment, but in this econometric model the statistically importance of distance was not meaningful. The main rationale related to this result may be due to globalization phenomenon, which is supposed to have diminished the inhibitory role of the distance. This latter is found in many forms ranging from geographical and cultural distance to time distance, and mostly it prevents more than favors the international trade and foreign investment. Econometric model showed that the size increases by 1 million dollar investment will increase by 0.0042 million. Size was the most significant variable in this model. The relationship between the foreign investment, the economic size and the distance is not very strong $(\mathrm{R}$ squared $=0,72$ ) and this may be because of other factors besides distance and size not captured in our model that can influence the level of foreign investment, such as: the potential of capital and human resources, labor force, the quality of the legal system, infrastructure - transportation networks, the number of phone calls, investment risk and barriers, protection of foreign investment, cultural similarities - common language, legal system similarity, taxation, bilateral trade, open economies, the unemployment rate, membership in international organizations, workforce education, unit labor costs, average wages, interest rates, financial market development, bilateral investment treaties, exchange rates, common currency, the cost of research - development and the rate of inflation. Including more of these variables in similar gravity models would be the challenge for future research studies in the field.

\section{References}

Gujarati, Damodar N. (fourth edition). (2004). Basic Econometric. McGraw Hill Companies

Hofmann Patricia. (2013). "International Trade, FDI and Economic Growth: Terms, Interdependencies and Research Focus." In The Impact of International Trade and FDI on Economic Growth and Technological Change, 9-27. New York Dordrecht London: Springer Heidelberg ISBN: 978-3-642-34580-7

Nello, Susan S. (2009). The European Union: Economics, Policies and History. Maidenhead: McGraw Hill Education ISBN 0-07-711813-8

Eurostat. EU direct investment outward flows by extra EU country of destination. http:/ / epp.eurostat.ec.europa.eu/tgm/table.do?tab=table\&init $=1 \&$ language $=$ en $\&$ pcode $=$ tec 0005 0\&plugin=1. (accessed March 1, 2014)

The World Bank. GDP (current US\$) http://data.worldbank.org/indicator/NY.GDP.MKTP.CD (accessed March 1, 2014)

http://www.xrates.com/average/?from=USD\&to=EUR\&amount=1.00\&year=2012. (accessed March 5, 2014) 
